\title{
Long-term outcome of neoadjuvant systemic therapy for locally advanced breast cancer in routine clinical practice
}

\author{
Domenico Angelucci • Nicola Tinari • Antonino Grassadonia • Ettore Cianchetti • Giampiero Ausili-Cefaro • \\ Laura Iezzi · Marinella Zilli · Simona Grossi · Lucia Anna Ursini • Maria Teresa Scognamiglio • Graziella Castrilli · \\ Michele De Tursi · Paolo Noccioli · Pasquale Cioff $\cdot$ Stefano Iacobelli $\cdot$ Clara Natoli
}

Received: 10 September 2012 / Accepted: 24 September 2012 / Published online: 10 October 2012

(c) The Author(s) 2012. This article is published with open access at Springerlink.com

\begin{abstract}
Purpose The aim of this study is to evaluate the long-term outcome of patients with locally advanced breast cancer treated with neoadjuvant systemic chemotherapy (NST) in routine clinical practice.

Methods Four hundred and nine patients were identified between January 1999 and December 2011. All patients received NST followed by surgery, adjuvant treatments and radiotherapy, as appropriate.

Results At Kaplan-Meier analysis, patients with surgical stage III disease were more likely to develop distant metastasis and die from breast cancer $(p<0.001)$. Luminal A and luminal B/HER2-negative patients had better prognosis; moreover, patients with hormone receptor (HR)-positive tumors had a significantly longer DRFS $(p<0.0049)$ and OS $(p<0.0001)$ compared with patients with HR-negative tumors as well as patients who underwent breast-conserving
\end{abstract}

D. Angelucci and N. Tinari are equal contributors to this paper.

D. Angelucci

Division of Pathology, 'SS. Annunziata' Hospital,

66013 Chieti, Italy

N. Tinari $\cdot$ A. Grassadonia $\cdot$ M. De Tursi $\cdot$ S. Iacobelli $~$

C. Natoli $(\bowtie)$

Department of Experimental and Clinical Sciences,

University 'G. d'Annunzio', 66013 Chieti, Italy

e-mail: natoli@unich.it

E. Cianchetti

Division of Surgical Senology,

Department of Experimental and Clinical Sciences,

University 'G. d'Annunzio', 66013 Chieti, Italy

G. Ausili-Cefaro

Radiation Oncology Department,

University 'G. d'Annunzio', 66013 Chieti, Italy surgery (DRFS and OS: $p<0.001$ ). In multivariate analysis, HR negativity $(p<0.001$ for both DRFS and OS), mastectomy (DRFS: $p=0.009$; OS: $p=0.05$ ) and stage III disease (DRFS: $p<0.001$; OS: $p=0.003$ ) were associated with shorter DRFS and OS.

Conclusions HR negativity, mastectomy and pathological stage III disease are the variables independently associated with a worse outcome in our cohort of patients. These data are of high interest since they derive from a very heterogeneous group of patients, treated with different neoadjuvant/ adjuvant regimens outside of clinical trials and with a long follow-up period.

Keywords Breast cancer - Neoadjuvant chemotherapy · Retrospective - Pathological complete response .

Prognostic factors

\author{
L. Iezzi $\cdot$ M. Zilli $\cdot$ M. T. Scognamiglio \\ Oncology Department, 'SS. Annunziata' Hospital, \\ 66013 Chieti, Italy \\ S. Grossi · P. Noccioli \\ Division of Surgical Senology, "G. Bernabeo" Hospital, \\ 66026 Ortona, $\mathrm{CH}$, Italy \\ L. A. Ursini \\ Division of Radiation Oncology, \\ 'SS. Annunziata' Hospital, 66013 Chieti, Italy \\ G. Castrilli \\ Division of Pathology, "G. Bernabeo" Hospital, \\ 66026 Ortona, $\mathrm{CH}$, Italy \\ P. Cioffi \\ Hospital Pharmacy, 'SS. Annunziata' Hospital, 66013 Chieti, Italy
}




\section{Background}

Neoadjuvant systemic therapy (NST) has been used in locally advanced breast cancer in order to convert a previously unresectable cancer into an operable one (Hortobagyi et al. 1988; Danforth et al. 1990; Schwartz et al. 1994). More recently, it has been widely administered in primarily operable breast cancer to reduce tumor volume and allow conservative surgery (Fisher et al. 1997; van der Hage et al. 2001; Semiglazov et al. 2011). The downstaging of the primary tumor and the increase in breast conservation rates seems to be the only clinical benefit of NST, given that several studies failed to demonstrate an improvement of overall survival compared with postoperative adjuvant chemotherapy (Fisher et al. 1997, 1998; Bear et al. 2006; Mauri et al. 2005). Breast cancer is a heterogeneous disease that varies widely in response to standard therapies and outcomes (Rouzier et al. 2005). In this perspective, NST represents an opportunity to determine the intrinsic resistance/ sensitiveness of breast cancer to chemotherapy. Moreover, the extent of residual disease in the breast and axillary surgical specimens after NST, classified according to the revised 2003 American Joint Committee on Cancer (AJCC) tumor-node-metastasis (TNM) staging system, has been reported to be associated with relapse and survival (Carey et al. 2005). Pathologic complete response (pCR) achieved after NST, when defined as non-invasive and non-in situ cancer in breast and nodes, is predictive of good prognosis and might be used as surrogate of survival (Kuerer et al. 1999; Kaufmann et al. 2006). However, patients with hormone receptors (HR)-positive tumors usually have low rates of pCR and maintain a good long-term outcome even in the presence of residual disease (no pCR) (Colleoni et al. 2009; Huober et al. 2010; Precht et al. 2010; Straver et al. 2010; Kim et al. 2010). In this group of patients, pCR fails to predict survival, emphasizing the importance of tumor biology rather than response to neoadjuvant chemotherapy as a prognostic marker in some subtypes of breast cancers (von Minckwitz et al. 2012).

The aim of this study is to evaluate the long-term outcome in a series of patients with locally advanced breast cancer consecutively treated with NST in our institution. All patients came from the routine clinical practice and were not included in clinical trials.

\section{Patients and methods}

Patient population

This is a single institution study. The charts of all patients with locally advanced breast cancer, performance status 0-2 (ECOG scale), consecutively treated with NST at the
Medical Oncology Division, University of Chieti Hospital between January 1999 and December 2011, were reviewed for this retrospective study. Four hundred and nine patients were identified. In all cases, diagnosis of invasive breast cancer was established by tru-cut biopsy of the primary tumor. Patients with bilateral and inflammatory breast cancer were excluded.

All patients received preoperative chemotherapy and those with HR-positive tumor received adjuvant hormonal therapy for 5 years. Chemotherapy regimens administered included: CMF (fluorouracil, methotrexate and cyclophosphamide); single-agent epirubicin; EC (epirubicin and cyclophosphamide); FEC (fluorouracil, epirubicin and cyclophosphamide); E-CMF (single-agent epirubicin followed by CMF); single-agent taxanes; ET (epirubicin and taxol); EC-T (EC followed by docetaxel); EC-TAXEL (EC followed by docetaxel and capecitabine) and other combinations including platinum compounds, vinorelbine and pegylated doxorubicin. Ninety-nine patients received adjuvant tamoxifen, 125 postmenopausal patients received aromatase inhibitors (anastrozole or letrozole) and 71 patients tamoxifen followed by exemestane. Ninety-four patients treated after 2005 and carrying HER2-positive tumors received Trastuzumab simultaneously with neoadjuvant chemotherapy and/or postoperatively to complete 1 year of treatment.

Surgical procedures consisted of mastectomy or breastconserving surgery (BCS). Sentinel node biopsy after NST was performed in 54 patients; axillary lymph node dissection was performed in $371(90.1 \%)$ patients, including 16 having positive sentinel nodes. Adjuvant breast radiotherapy was delivered to patients who underwent BCS as well as to patients who underwent mastectomy but had initial stage cT3, $\mathrm{cN} 2$ or $\mathrm{cN} 3$ disease.

\section{Pathological assessments}

Estrogen (ER)/progesterone receptors (PR) and human epidermal growth factor type 2 receptor (HER2) were determined on pretreatment biopsy and on surgical specimens by immunohistochemistry. HR status was considered positive if $\geq 10 \%$ of tumor cells stained for ER and/or PR. HER2 status was assessed by HercepTest (Dako Italia, Milan, Italy). Samples were scored as follows: score 0 , membrane staining in $\leq 10 \%$ of tumor cells; score $1+$, partial and/or faint membrane staining in $>10 \%$ of tumor cells; score $2+$, weak to moderate, complete membrane staining in $>10 \%$ tumor cells and score $3+$, strong, complete membrane staining in $>10 \%$ of tumor cells. FISH or CISH was carried out on all tumors with HercepTest 2+. Tumors with a score of $3+$ by immunohistochemistry (IHC) or gene amplification by FISH were considered as HER2 positive. Immunohistochemical detection of Ki-67 was performed using the MIB-1 
antibody (Dowsett et al. 2011). Nuclear grade was assessed according to the Nottingham grading system (Elston and Ellis 1991).

We could not exactly define breast cancer intrinsic subtypes with immunohistochemistry in all tumors (Goldhirsch et al. 2011), since Ki-67 assessment was not available in $172(42.0 \%)$ samples. So we classified tumors as follows: (1) luminal A and luminal B/HER2 negative; (2) luminal B/HER2 positive; (3) HER2 enriched; (4) triple negative (Houssami et al. 2012).

pCR was defined as non-invasive cancer within the breast (ypT0/is) and lymph node (ypN0), also classified as Stage 0 (Kuerer et al. 1999; Kaufmann et al. 2010). Pathological stages were categorized according to the American Joint Committee on Cancer Staging Manual, 7th ed. (Edge et al. 2010).

Locoregional recurrence (LRR) was defined as any chest wall recurrence in those who underwent mastectomy, any ipsilateral in-breast recurrence in those achieving breast conservation and any recurrence in the axillary, supraclavicular or internal mammary nodes.

\section{Data collection}

Medical records for all patients were reviewed retrospectively and the cut off date for follow-up set on December 31, 2011. Clinical and pathological characteristics for each patient were entered on an anonymized database. Since patients' enrollment began in 1999, complete information was not available for all 409 patients; thus, denominators may vary throughout the article. The follow-up contacts were carried out at 6-month intervals over the first 5 years, and at 12-month intervals thereafter.

Study endpoints and statistics

The primary endpoint of this study was overall survival (OS), defined as the interval between the time of surgery and the date of death from any cause or censoring. Survivors were censored at the date of last contact. The secondary endpoints were rate of $\mathrm{pCR}$ and distant relapse-free survival (DRFS), defined as the time from breast surgery to the first occurrence of distant metastasis or intercurrent deaths without distant recurrence.

A two-sided level of significance of 0.05 was applied to all statistical tests. In univariate analysis, the relationships between patients/tumor characteristics and pCR were assessed by Pearson's $\chi^{2}$ or Fisher's exact test, as appropriate. A stepwise multivariate logistic regression was used to identify independent predictors of pCR among baseline patients/tumor characteristics. Survival curves were derived from Kaplan-Meier estimates and compared by log-rank test and hazard ratio (HR) (Massarweh et al. 2006). A mul- tivariate Cox proportional hazard model was carried out to assess the relative influence of prognostic factors on survival (De Placido et al. 2003). All statistical analyses were performed using the SPSS Statistic software version 19 (IBM, Armonk, New York).

\section{Results}

Baseline patient and tumor characteristics

Clinical and pathological baseline characteristics of patients are shown in Table 1 . The median age was 48.8 years (range 25-80), with 20 (4.9\%) patients being younger than 35 years and $15(3.7 \%)$ older than 70 years. Clinical tumor size was $\geq 3 \mathrm{~cm}$ in 175 (42.8\%) patients; $346(84.6 \%)$ patients had ductal carcinoma. Tumor grade was $1-2$ in $289(70.7 \%)$ and grade 3 in $87(21.2 \%)$ patients. Ki-67 was available in 237 (58\%) cases and was $>14 \%$ in $135(56.9 \%)$. Tumors were classified in four molecular subtypes according to the tumor staining for ER/ PR and HER2 status: 211 (51.9\%) were HER2 negative, luminal A or luminal B (ER and/or PR positive); 84 (20.6\%) were HER2 positive, luminal B (ER and/or PR positive); 53 (13.0\%) were HER2 enriched (ER and PR negative, HER2 positive); 59 (14.5\%) were triple negative (ER and PR negatives, HER2 negative). Most patients, 237 $(58.0 \%)$, received chemotherapy based on anthracycline and taxanes. Among 137 women with HER2-positive tumor, $43(31.4 \%)$, diagnosed before 2005, were not treated with Trastuzumab, $29(21.2 \%)$ received adjuvant Trastuzumab and $65(47.4 \%)$ received neoadjuvant and adjuvant Trastuzumab. A total of 300 (73.3\%) patients received more than four cycles of chemotherapy.

\section{Relationship between baseline characteristics and pCR}

In the univariate analysis, pCR was significantly associated with tumor grade, proliferative activity, molecular subtype, type of NST and number of chemotherapy cycles (Table 1), patients with the worst prognostic factors having the best pCR rates. In the multivariate analysis, only HR-negative tumors, independently from HER2 status (HER2 enriched: $p=0.043$; triple negative: $p=0.002$ ) and the use of neoadjuvant Trastuzumab $(p=0.035)$ were significantly associated with higher pCR rates (Table 2).

\section{Patients' characteristics after NST}

Patients' characteristics after completion of NST are reported in Table 3. BCS was performed in $241(58.9 \%)$ patients and mastectomy in the remaining $168(41.1 \%)$. Absence of cancer in the breast (ypT0) was found in 75 
Table 1 Association of baseline factors and pCR in univariate analysis

\begin{tabular}{|c|c|c|c|}
\hline & No. $(\%)$ & pCR no. $(\%)$ & $p$ value \\
\hline \multicolumn{4}{|l|}{ Age } \\
\hline \multicolumn{4}{|l|}{$\begin{array}{r}\text { Median age } 48.8 \text { years } \\
\text { (range } 25-80 \text { years })\end{array}$} \\
\hline$\leq 35$ years & $20(4.9)$ & $5(25.0)$ & \\
\hline$>35$ years & $389(95.1)$ & $56(14.4)$ & n.s. \\
\hline \multicolumn{4}{|l|}{ Clinical $T$} \\
\hline$\leq 3 \mathrm{~cm}$ & $213(52.1)$ & $30(14.0)$ & \\
\hline$\geq 3 \mathrm{~cm}$ & $175(42.8)$ & $30(17.1)$ & \\
\hline Unknown $^{\mathrm{a}}$ & $21(5.1)$ & $1(4.8)$ & n.s. \\
\hline \multicolumn{4}{|l|}{ Histologic type } \\
\hline Ductal & $346(84.6)$ & $51(14.7)$ & \\
\hline Lobular & $57(14.0)$ & $10(17.5)$ & \\
\hline Others & $6(1.4)$ & 0 & n.s. \\
\hline \multicolumn{4}{|l|}{ Grade } \\
\hline $1-2$ & $289(70.7)$ & 25 (8.6) & \\
\hline 3 & $87(21.2)$ & $19(21.8)$ & \\
\hline Unknown $^{\mathrm{a}}$ & $33(8.1)$ & $17(51.5)$ & 0.001 \\
\hline \multicolumn{4}{|l|}{$K i-67$} \\
\hline$\leq 14 \%$ & $102(43.1)$ & $4(3.9)$ & \\
\hline$>14 \%$ & $135(56.9)$ & $33(22.2)$ & \\
\hline Unknown $^{\mathrm{a}}$ & $172(50.0)$ & $24(14.0)$ & 0.000 \\
\hline \multicolumn{4}{|l|}{ Molecular subtype } \\
\hline Luminal A \& B/HER2 negative & $211(51.9)$ & $12(5.7)$ & \\
\hline Luminal B/HER2 positive & $84(20.6)$ & $14(16.6)$ & \\
\hline HER2 enriched & $53(13.0)$ & $18(33.9)$ & \\
\hline Triple negative & $59(14.5)$ & $17(28.8)$ & \\
\hline Unknown $^{\mathrm{a}}$ & $2(0.04)$ & & 0.000 \\
\hline \multicolumn{4}{|l|}{ Type of NST } \\
\hline Various & $107(26.1)$ & $5(4.5)^{*}$ & \\
\hline Anthracycline and taxane & $237(58.0)$ & $30(12.6)^{*}$ & \\
\hline Chemotherapy + Trastuzumab & $65(15.9)$ & $26(40.0)$ & 0.000 \\
\hline \multicolumn{4}{|l|}{ No. of chemotherapy cycles } \\
\hline$\leq 4$ & $109(26.7)$ & $7(6.4)$ & \\
\hline$>4$ & $300(73.3)$ & $54(18.0)$ & 0.004 \\
\hline
\end{tabular}

* $10.2 \%$ pCR in patients treated with chemotherapy only

${ }^{\text {a }}$ Unknown were not included in univariate analysis

(18.3\%) patients; absence of cancer in lymph nodes (ypN0) in $181(44.2 \%)$ patients and a total of $61(14.9 \%)$ patients had a pCR, that is, absence of invasive cancer both in breast and nodes. Most patients received adjuvant treatments: 125 (30.6\%) patients had only hormonal therapy, $54(13.2 \%)$ only chemotherapy, $105(25.6 \%)$ chemotherapy followed by hormonal therapy and 94 (23.0\%) received adjuvant Trastuzumab either alone (33 patients), with hormonal therapy (39 patients), with chemotherapy (11 patients) or with chemotherapy and hormonal therapy (11 patients). Adjuvant radiotherapy was delivered to 310
Table 2 Association of baseline factors and pCR in multivariate analysis

\begin{tabular}{|c|c|c|c|}
\hline & Odds rat & $95 \% \mathrm{CI}$ & $p$ value \\
\hline \multicolumn{4}{|l|}{ Age } \\
\hline$>35$ years & & Reference & \\
\hline$\leq 35$ years & 2.081 & $0.426-10.175$ & n.s. \\
\hline \multicolumn{4}{|l|}{ Clinical $T$} \\
\hline$\leq 3 \mathrm{~cm}$ & & Reference & \\
\hline$\geq 3 \mathrm{~cm}$ & 1.040 & $0.414-2.611$ & n.s. \\
\hline \multicolumn{4}{|l|}{ Histologic type } \\
\hline Other & & Reference & \\
\hline Ductal & 2.965 & $0.327-6.424$ & n.s. \\
\hline Lobular & 5.995 & $0.213-10.785$ & n.s. \\
\hline \multicolumn{4}{|l|}{ Grade } \\
\hline $1-2$ & & Reference & \\
\hline 3 & 1.275 & $0.418-3.885$ & n.s. \\
\hline \multicolumn{4}{|l|}{$K i-67$} \\
\hline$\leq 14 \%$ & & Reference & \\
\hline$>14 \%$ & 3.689 & $0.899-15.132$ & n.s. \\
\hline \multicolumn{4}{|l|}{ Molecular subtype } \\
\hline Luminal $\mathrm{A}$ and $\mathrm{B} / \mathrm{HER} 2$ negative & & Reference & \\
\hline Luminal B/HER2 positive & 1.564 & $0.252-9.716$ & n.s. \\
\hline HER2 enriched & 6.090 & $1.062-34.921$ & 0.043 \\
\hline Triple negative & 10.646 & $2.307-40.125$ & 0.002 \\
\hline \multicolumn{4}{|l|}{ Type of NST } \\
\hline Various & 2.290 & Reference & n.s. \\
\hline Anthracycline and taxane & 11.334 & $0.300-17.419$ & 0.035 \\
\hline Chemotherapy + Trastuzumab & & $1.182-108.719$ & \\
\hline \multicolumn{4}{|l|}{ No. of chemotherapy cycles } \\
\hline$\leq 4$ & 2.158 & Reference & n.s. \\
\hline$>4$ & & $0.308-15.143$ & \\
\hline
\end{tabular}

(75.8\%) patients, including 101 patients who underwent mastectomy.

Survival

Median follow-up was 42.1 months (range $0.8-$ 147.3 months). During follow-up, 25 (6.1\%) patients had local relapse, $84(20.5 \%)$ had distant metastases and 53 (13.0\%) died. We evaluated patients' outcome in relation to different variables such as pCR, stage at surgery, tumor molecular subtype, use of Trastuzumab for HER2-positive tumors, type of surgery and breast radiotherapy. The occurrence of local relapse was not correlated with stage of disease at surgery, type of surgery and radiation therapy, while it was more frequent among patients with HR-negative tumors ( $p=0.007$ by Pearson's $\chi^{2}$ ).

At Kaplan-Meier analysis of the whole population, pCR was not found to be a prognostic factor for DRFS and OS (not shown). However, excluding from the analyses 
Table 3 Clinical characteristics of patients after NST therapy

\begin{tabular}{|c|c|}
\hline & No. $(\%)$ \\
\hline \multicolumn{2}{|l|}{ Type of surgery } \\
\hline $\mathrm{BCS}$ & $241(58.9)$ \\
\hline Mastectomy & $168(41.1)$ \\
\hline \multicolumn{2}{|l|}{ Residual tumor size } \\
\hline урт0 & $75(18.3)$ \\
\hline урT1 & $180(44.0)$ \\
\hline урT2 & $116(28.3)$ \\
\hline урт3 & $38(9.2)$ \\
\hline \multicolumn{2}{|l|}{ No. of metastatic nodes } \\
\hline None & $181(44.2)$ \\
\hline $1-3$ & $109(26.6)$ \\
\hline $4-9$ & $70(17.1)$ \\
\hline$\geq 10$ & $49(11.9)$ \\
\hline \multicolumn{2}{|l|}{ Posttherapy stage } \\
\hline 0 & $61(14.9)$ \\
\hline I & $92(22.5)$ \\
\hline II & $129(31.5)$ \\
\hline III & $127(31.9)$ \\
\hline \multicolumn{2}{|l|}{ Adjuvant treatment } \\
\hline Nil & $31(7.6)$ \\
\hline Hormonal therapy & $125(30.6)$ \\
\hline Chemotherapy & $54(13.2)$ \\
\hline Chemotherapy followed by hormonal therapy & $105(25.6)$ \\
\hline Trastuzumab & $94(23.0)$ \\
\hline \multicolumn{2}{|l|}{ Radiotherapy } \\
\hline Yes & $310(75.8)$ \\
\hline No & $99(24.2)$ \\
\hline \multicolumn{2}{|l|}{ Mastectomy } \\
\hline With radiation & $101(60.1)$ \\
\hline Without radiation & $67(39.8)$ \\
\hline
\end{tabular}

patients with luminal A or luminal B/HER2-negative tumors (a group of patients with favorable outcome, representing $51.9 \%$ of the entire study population), pCR resulted predictive of better DRFS $(p=0.028$ : HR $=0.37$, $95 \% \mathrm{CI}=0.19-0.72)$ with a trend toward significance for OS $(p=0.06 ; \mathrm{HR}=0.34,95 \% \mathrm{CI}=0.16-0.77)$ (Fig. 1a, b). Patients with higher stage of disease after NST were more likely to develop distant metastasis and die from breast cancer (Fig. 2a, b; $p<0.001$ ). Patients who achieved pCR (stage 0 ) had DRFS and OS rates of $87.1 \%$ (95 \% CI: 77.3-96.9\%) and $92.0 \%$ (95\% CI: 84.8-99.2\%), respectively, similar to those of patients with surgical stage I (DRFS: $85.9 \%$; $95 \%$ CI: $77.1-94.7 \%$ and OS: $80.4 \%$; $95 \%$ CI: 66.9-93.9\%). Stage II patients had DRFS rates of $61.3 \%$ (95\% CI: $39.7-82.9 \%$ ) and OS rates of $76.8 \%$ (95\% CI: 55.2-98.4\%), while stage III patients had DRFS rates of $48.5 \%$ (95\% CI: 35.4-61.6\%) and OS rates of $44.6 \%$ (95\% CI: $17.7-71.5 \%)$.
Significant differences in DRFS $(p=0.006)$ and OS $(p=0.006)$ were observed among patients with different tumor molecular subtypes (Fig. 3a, b), the group of patients with luminal A or luminal B/HER2-negative tumors showing a better prognosis. Moreover, patients with HR-positive tumors had a significant longer DRFS $(p<0.005$ : $\mathrm{HR}=0.54,95 \% \mathrm{CI}=0.35-0.85)$ and $\mathrm{OS}(p<0.0001$ : $\mathrm{HR}=0.34,95 \% \mathrm{CI}=0.19-0.63)$ compared with patients with HR-negative tumors (Fig. 3c, d). When survival analysis was stratified according to HER2 status, the DRFS and OS advantage for HR-positive tumors was limited to the HER2-negative population ( $p=0.016: \mathrm{HR}=0.50,95 \%$ $\mathrm{CI}=0.25-0.97$ and $p<0.0001: \mathrm{HR}=0.25,95 \% \mathrm{CI}=0.11-$ 0.60, respectively) (Fig. 3e, f), while among HER2-positive group, HR positivity was predictive of a longer DRFS ( $p=0.044: \mathrm{HR}=0.50,95 \% \mathrm{CI}=0.24-1.0)$, but not OS (not shown). In our population, neither HER2 status nor the use of Trastuzumab in the HER2-positive patients was statistically associated with clinical outcome (not shown).

Patients who underwent BCS were more likely to have a better DRFS $(p<0.0001: \mathrm{HR}=0.36,95 \% \mathrm{CI}=0.23-0.55)$ and $\mathrm{OS}(p=0.0014: \mathrm{HR}=0.42,95 \% \mathrm{CI}=0.24-0.72)$ compared with those who required mastectomy (Fig. 4a, b). No differences in survival were observed in patients treated with or without radiotherapy after surgery (not shown).

In multivariate analysis, the variables independently associated with shorter DRFS and OS were absence of HR expression (DRFS and OS: $p<0.001$ ), mastectomy (DRFS: $p=0.009$; OS: $p=0.05$ ) and stage III disease (DRFS: $p<0.001$; OS: $p=0.003$ ), whereas the molecular subtype luminal B/HER2-positive tumors reached statistical significance for OS ( $p=0.035)$, but not for DRFS (Tables 4, 5).

\section{Discussion}

In this retrospective study, we show that HR negativity, requirement for mastectomy and pathological stage III disease are independently associated with a worse outcome in breast cancer patients treated with NST in clinical practice. These data are of high interest since they derive from a very heterogeneous group of patients, treated with different neoadjuvant/adjuvant regimens outside of clinical trials and with a long follow-up period.

During the course of the last 12 years, the adjuvant treatment of patients affected by early breast cancer is profoundly changed, going from first generation regimens like $\mathrm{CMF}$ and epirubicin-CMF, second generation regimens like FEC to third generation regimens, like EC followed by docetaxel (Sachelarie et al. 2006; Peto et al. 2012). Also, we delivered Trastuzumab in the adjuvant treatment of HER2-positive tumors from 2005 and in the neoadjuvant 

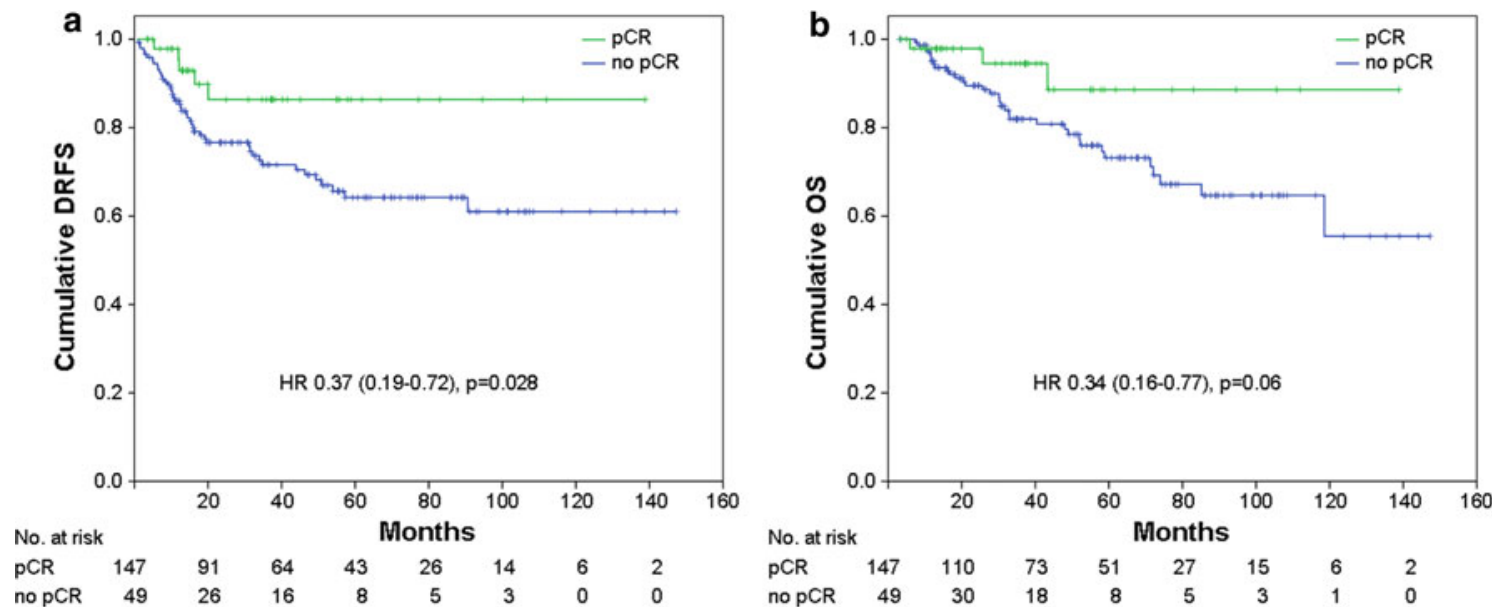

Fig. 1 a Distant relapse free survival $(D R F S)$ and b overall survival $(O S)$ stratified by pathological complete response $(p C R)$ for the whole population, excluding patients with HR-positive/HER2-negative tumors
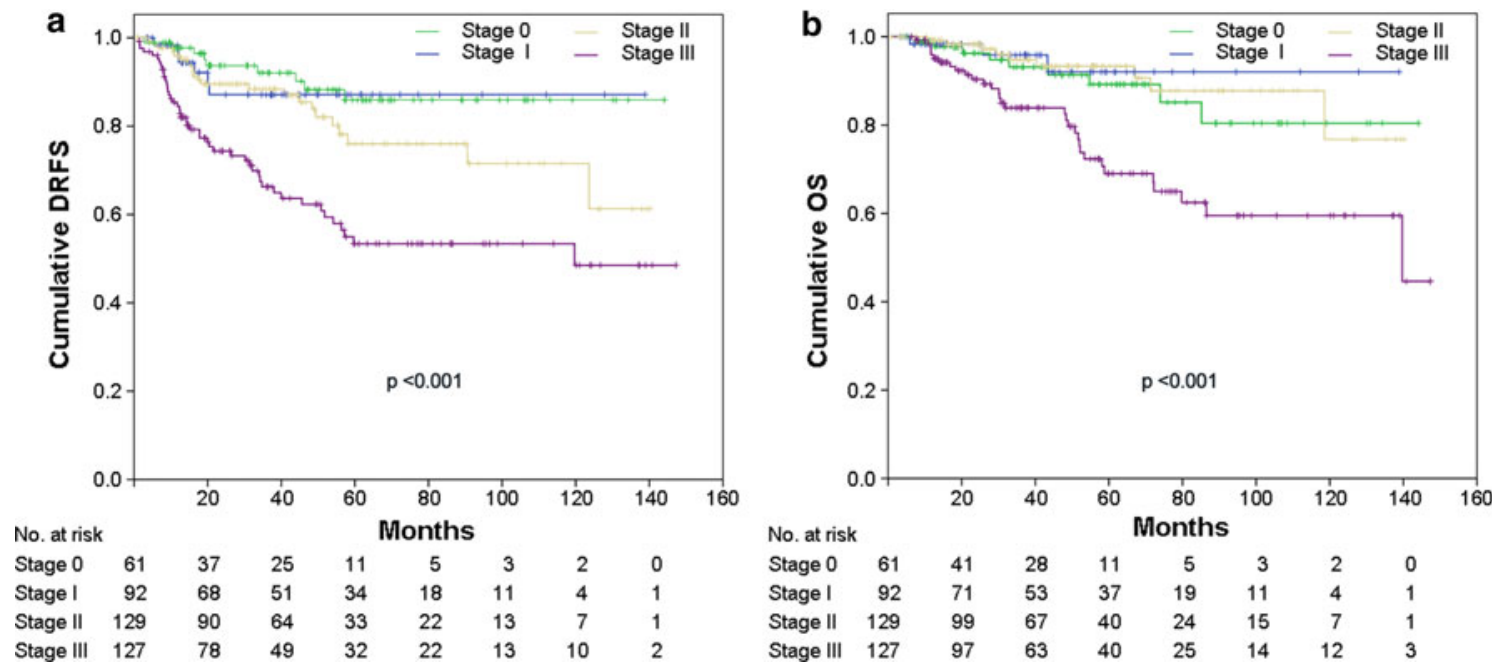

Fig. 2 a Distant relapse free survival $(D R F S)$ and $\mathbf{b}$ overall survival $(O S)$ stratified by pathological stage after systemic neoadjuvant chemotherapy

setting from 2006 (Romond et al. 2005; Arteaga et al. 2012). Finally, surrogate definitions of intrinsic subtypes with immunohistochemistry have only recently proven to be effective in defining prognosis and selecting adjuvant therapy in early stage breast cancer patients (Cheang et al. 2009; Nielsen et al. 2010; Goldhirsch et al. 2011).

In our study, high tumor grade, high proliferative activity, HR-negativity expression in tumor biopsy, the use of neoadjuvant Trastuzumab and an increase in number of chemotherapy cycles resulted significantly associated with higher rates of $\mathrm{pCR}$ at univariate analysis, consistent with current literature (Colleoni et al. 2009; Huober et al. 2010; Kim et al. 2010; Precht et al. 2010; Straver et al. 2010; Untch et al. 2011; von Minckwitz et al. 2011), but only HR negativity and neoadjuvant Trastuzumab were confirmed at multivariate analysis. The association between HR negativity and pCR has been observed also in a recently published meta-analysis based on 20 studies providing data with classification of HER2 positivity according to HR status (Houssami et al. 2012). Their estimates of pCR were $8.3 \%$ in the luminal A and luminal B/HER2-negative subtype; $18.7 \%$ in the luminal B/HER2-positive subtype; $38.9 \%$ in the HER2-enriched subtype and $31.1 \%$ in the triple negative subtype (Houssami et al. 2012).

However, although most neoadjuvant chemotherapy trials have shown that pCR is associated with a favorable outcome in terms of DRFS and OS (Kuerer et al. 1999; Kaufmann et al. 2006; Buzdar et al. 2007; Dawood et al. 2008), in our cohort pCR was not predictive of better prognosis. This discordance is not explained by the definition of pCR we applied, since it is now the most commonly used. Different definitions for pCR have been used in different clinical trials, varying according to site (i.e., breast only or both breast and axillary) and residual dis- 

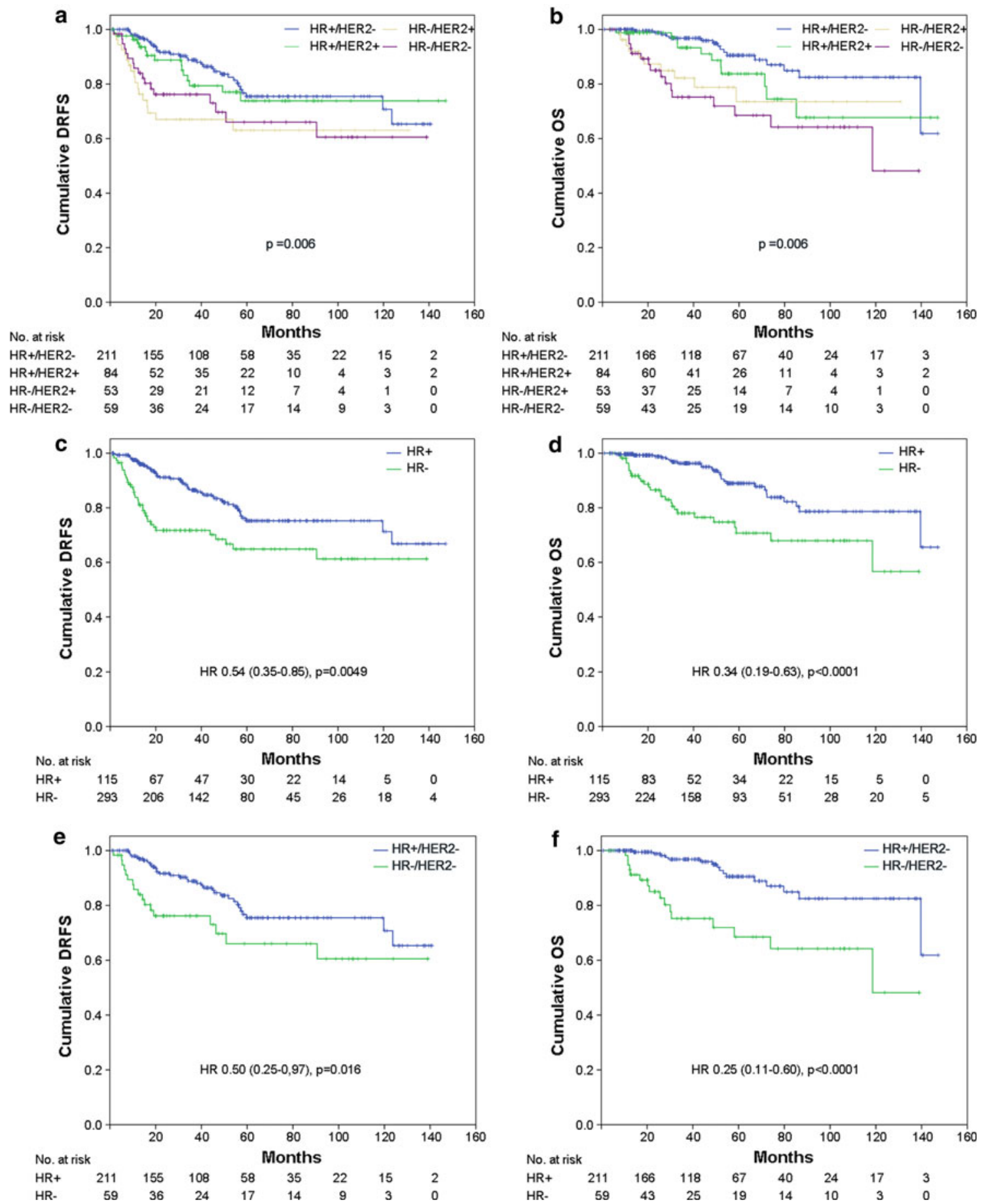

Fig. 3 a, c, e Distant relapse free survival $(D R F S)$ and $\mathbf{b}, \mathbf{d}, \mathbf{f}$ overall survival $(O S)$ stratified by molecular subtypes for the whole population $(\mathbf{a}, \mathbf{b})$, by hormone receptor $(H R)$ status $(\mathrm{HR}+$ and $\mathrm{HR}-$ ) for the

ease (i.e., presence of focal invasive cancer, non-invasive cancer residuals or absence of invasive and non-invasive cancer) (Sataloff et al. 1995; Bear et al. 2003; Green et al. 2005; von Minckwitz et al. 2010). Absence of invasive and non-invasive cancer has been reported to be associated with a better prognosis (von Minckwitz et al. 2010).

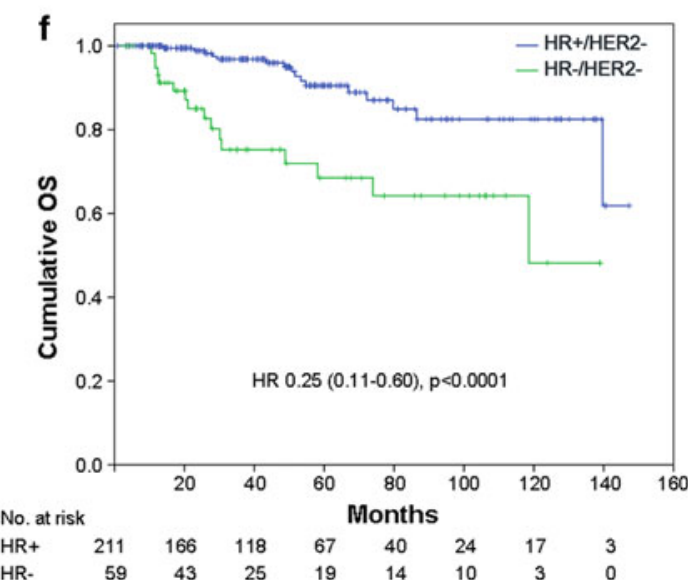

whole population (c, d) and by HR status for patients with HER2-negative tumors $(\mathbf{e}, \mathbf{f})$

The incidence of residual non-invasive cancer in our study (only six patients had residual in situ ductal carcinoma in the final pathologic examination), is too low to justify the poorer outcome observed in the whole population. More importantly, most of the patients in the study (211 patients, $51.9 \%$ ) had luminal A or luminal B/HER2- 

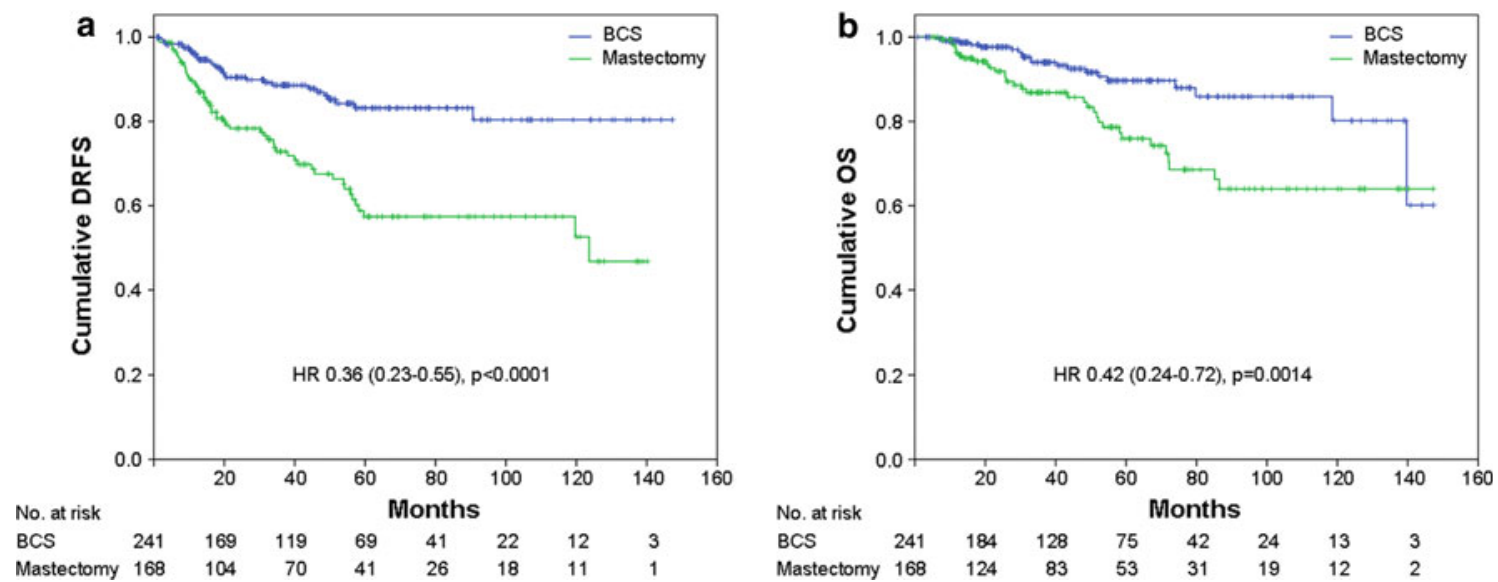

Fig. 4 a Distant relapse free survival $(D R F S)$ and b overall survival $(O S)$ stratified by type of surgery. $B C S$ breast conservative surgery

Table 4 Multivariable proportional hazard regression model predicting DRFS

\begin{tabular}{lllll}
\hline & Parameter estimate & Hazard ratio & $95 \%$ CI & $p$ value \\
\hline $\begin{array}{l}\text { Age } \\
>35 \text { years }\end{array}$ & & & & \\
$\leq 35$ years & 0.158 & & Reference & \\
Histologic type & & 1.171 & $0.457-3.003$ & n.s. \\
Lobular & & & & \\
Ductal & 0.065 & & Reference & n.s. \\
Others & 0.187 & 1.067 & $0.568-2.006$ & n.s. \\
Molecular subtype preNST & & 1.206 & $0.247-5.874$ & \\
Luminal A and B/HER2 negative & & & & \\
Luminal B/HER2 positive & 0.591 & & Reference & \\
HER2 enriched & 1.678 & 1.807 & $0.970-3.365$ & 0.062 \\
Triple negative & 1.141 & 5.354 & $2.747-10.435$ & 0.000 \\
Type of surgery & & 3.130 & $1.703-5.752$ & 0.000 \\
BCS & & & & \\
Mastectomy & & & Reference & \\
Stage & 0.643 & 1.903 & $1.170-3.093$ & 0.009 \\
0 & & & & \\
I & 0.185 & 1.203 & $0.419-3.454$ & n.s. \\
II & 0.751 & 2.119 & $0.825-5.443$ & n.s. \\
III & 1.810 & 6.108 & $2.376-15.707$ & 0.000 \\
\hline
\end{tabular}

negative tumors, a subgroup considered to have slowly proliferating and less chemotherapy responsive tumors. In these patients, pCR has been shown to be not associated with prognosis (von Minckwitz et al. 2010). The high number of patients included in the luminal A or luminal B/HER2-negative subgroup in our study could have diluted the effect of pCR on outcome. Indeed, when these patients were excluded from the analyses, $\mathrm{pCR}$ was significantly associated with longer DRFS and OS.

The outcome of patients included in this study was significantly affected by stage at surgery, HR expression and type of surgery. Several studies have showed that a higher stage after NST is predictive of poor prognosis (Fisher et al.
1998; Cance et al. 2002; Carey et al. 2005). Consistently, we found that patients with stage III disease had a significantly shorter DRFS and OS. Lack of HR expression is another well-established parameter associated with poor prognosis (Osborne and McGuire 1979; McGuire et al. 1986). In our study, after a follow-up of about 12 years, patients with HR-negative tumors had a significantly lower rate of DRFS (61 vs. $67 \%, p<0.001)$ and OS (56.6 vs. $65.5 \%, p<0.001)$ compared with patients with HR-positive tumors, independently from HER2 status, at least for DRFS. The OS advantage for HR positivity was lost in the subgroup of HER2-positive tumors. This might be explained by the lower responsiveness of HR- and HER2- 
Table 5 Multivariable proportional hazard regression model predicting OS

\begin{tabular}{|c|c|c|c|c|}
\hline & Parameter estimate & Hazard ratio & $95 \% \mathrm{CI}$ & $p$ value \\
\hline \multicolumn{5}{|l|}{ Age } \\
\hline$>35$ years & & & Reference & n.s. \\
\hline$\leq 35$ years & 0.178 & 1.195 & $0.404-3.533$ & \\
\hline \multicolumn{5}{|l|}{ Histologic type } \\
\hline Lobular & & & Reference & \\
\hline Ductal & 0.424 & 1.528 & $0.590-3.955$ & n.s. \\
\hline Others & 0.509 & 1.664 & $0.170-16.266$ & n.s. \\
\hline \multicolumn{5}{|l|}{ Molecular subtype preNST } \\
\hline Luminal $\mathrm{A}$ and $\mathrm{B} / \mathrm{HER} 2$ negative & & & Reference & \\
\hline Luminal B/HER2 positive & 0.846 & 2.330 & $1.062-5.111$ & 0.035 \\
\hline HER2 enriched & 1.751 & 5.761 & $2.438-13.610$ & 0.000 \\
\hline Triple negative & 1.696 & 5.453 & $2.620-11.350$ & 0.000 \\
\hline \multicolumn{5}{|l|}{ Type of surgery } \\
\hline $\mathrm{BCS}$ & & & Reference & \\
\hline Mastectomy & 0.606 & 1.834 & $1.170-3.093$ & 0.056 \\
\hline \multicolumn{5}{|l|}{ Stage } \\
\hline 0 & & & Reference & \\
\hline I & 0.726 & 2.066 & $0.547-7.808$ & n.s. \\
\hline II & 0.466 & 1.593 & $0.409-6.205$ & n.s. \\
\hline III & 1.900 & 6.683 & $1.877-23.801$ & 0.003 \\
\hline
\end{tabular}

positive tumors to the effect of adjuvant endocrine therapy (De Placido et al. 2003; Massarweh et al. 2006).

BCS was carried out in $241(58.9 \%)$ patients and this is in agreement with the percentage of BCS performed after NST reported in clinical trials (Bear et al. 2006; Fisher et al. 1998; Alm El-Din and Taghian 2009). These patients had a significantly better prognosis in terms of DRFS and OS compared with patients who underwent mastectomy. Similar data are presented by other authors who related these findings to patients' selection: patients were more likely to have BCS if they presented with earlier stage disease or a clinical complete or greater than $50 \%$ partial response (Schwartz et al. 1994; Kuerer et al. 1999). In our cohort, this advantage was independent of age, histologic type, molecular subtype and surgical stage, but we agree that the achievement of BCS can be considered as an indirect measure of clinical response of the primary tumor, parameter not included in our multivariate analyses since we could not uniformly assess it throughout our patient population. In this study, clinical response was evaluated before, during and after neoadjuvant chemotherapy either by physical examination or by echographic and mammographic measurements, but the lack of standardization did not allow us to include clinical response as a variable for the multivariate analyses. Considering achievement of BCS as a surrogate marker of primary tumor response, our results suggest that the clinical response to NST is a strong predictive factor of good outcome. Some neoadjuvant trials have provided evidence of the prognostic value of clinical response, even when it was not correlated with pCR (Hortobagyi et al. 1988; Jacquillat et al. 1991; Cameron et al. 1997; Pierga et al. 2003).

During follow-up, 25 (6.1\%) patients had LRR, which was related neither to the type of surgery nor to radiotherapy. These data are in agreement with those of other authors reporting a rate of LRR ranging from 6 to $10 \%$, with a trend toward higher rates in patients with basal-like subtypes (Chen et al. 2004; Tanioka et al. 2010; Meyers et al. 2011; Min et al. 2011).

In conclusion, this retrospective neoadjuvant study, based on a population of patients treated in the practice of clinical medicine, shows that HR negativity, stage III disease at surgery and failure to achieve BCS after NST are independent factors negatively associated with prognosis. Moreover, the results of this study further confirm that pCR is of no prognostic value in patients with luminal A or luminal B/HER2-negative tumors. These patients, therefore, should not be included in neoadjuvant clinical trials whose primary end point is pCR, as suggested by other authors (Eiermann et al. 2001; Berruti et al. 2011).

Acknowledgments Supported by the Consorzio Interuniversitario Nazionale per Bio-Oncologia (CINBO) and by the Gruppo Interdisciplinare Cure Oncologiche (GICO), Asl Lanciano-Vasto-Chieti. The authors are grateful to Mrs. Camille St. Pierre for careful reviewing of the manuscript.

Conflict of interest None of the authors has any potential financial conflict of interest related to this manuscript. 
Open Access This article is distributed under the terms of the Creative Commons Attribution License which permits any use, distribution, and reproduction in any medium, provided the original author(s) and the source are credited.

\section{References}

Alm El-Din MA, Taghian AG (2009) Breast conservation therapy for patients with locally advanced breast cancer. Semin Radiat Oncol 19(4):229-235. doi:10.1016/j.semradonc.2009.05.005

Arteaga CL, Sliwkowski MX, Osborne CK, Perez EA, Puglisi F, Gianni L (2012) Treatment of HER2-positive breast cancer: current status and future perspectives. Nat Rev Clin Oncol 9(1):16-32. doi:10.1038/nrclinonc.2011.177

Bear HD, Anderson S, Brown A, Smith R, Mamounas EP, Fisher B, Margolese R, Theoret H, Soran A, Wickerham DL, Wolmark N (2003) The effect on tumor response of adding sequential preoperative docetaxel to preoperative doxorubicin and cyclophosphamide: preliminary results from National Surgical Adjuvant Breast and Bowel Project Protocol B-27. J Clin Oncol 21(22):41654174. doi:10.1200/jco.2003.12.005

Bear HD, Anderson S, Smith RE, Geyer CE Jr, Mamounas EP, Fisher B, Brown AM, Robidoux A, Margolese R, Kahlenberg MS, Paik S, Soran A, Wickerham DL, Wolmark N (2006) Sequential preoperative or postoperative docetaxel added to preoperative doxorubicin plus cyclophosphamide for operable breast cancer: National Surgical Adjuvant Breast and Bowel Project Protocol B-27. J Clin Oncol 24(13):2019-2027. doi:10.1200/jco.2005. 04.1665

Berruti A, Generali D, Kaufmann M, Puztai L, Curigliano G, Aglietta M, Gianni L, Miller WR, Untch M, Sotiriou C, Daidone M, Conte P, Kennedy D, Damia G, Petronini P, Di Cosimo S, Bruzzi P, Dowsett M, Desmedt C, Mansel RE, Olivetti L, Tondini C, Sapino A, Fenaroli P, Tortora G, Thorne H, Bertolini F, Ferrozzi F, Danova M, Tagliabue E, de Azambuja E, Makris A, Tampellini M, Dontu G, Van't Veer L, Harris AL, Fox SB, Dogliotti L, Bottini A (2011) International expert consensus on primary systemic therapy in the management of early breast cancer: highlights of the Fourth Symposium on Primary Systemic Therapy in the Management of Operable Breast Cancer, Cremona, Italy (2010). J Natl Cancer Inst Monogr 43:147-151. doi:10.1093/jncimonographs/lgr037

Buzdar AU, Valero V, Ibrahim NK, Francis D, Broglio KR, Theriault RL, Pusztai L, Green MC, Singletary SE, Hunt KK, Sahin AA, Esteva F, Symmans WF, Ewer MS, Buchholz TA, Hortobagyi GN (2007) Neoadjuvant therapy with paclitaxel followed by 5-fluorouracil, epirubicin, and cyclophosphamide chemotherapy and concurrent trastuzumab in human epidermal growth factor receptor 2-positive operable breast cancer: an update of the initial randomized study population and data of additional patients treated with the same regimen. Clin Cancer Res 13(1):228-233. doi:10.1158/1078-0432.ccr-06-1345

Cameron DA, Anderson ED, Levack P, Hawkins RA, Anderson TJ, Leonard RC, Forrest AP, Chetty U (1997) Primary systemic therapy for operable breast cancer-10-year survival data after chemotherapy and hormone therapy. Br J Cancer 76(8):1099-1105

Cance WG, Carey LA, Calvo BF, Sartor C, Sawyer L, Moore DT, Rosenman J, Ollila DW, Graham M, 2nd (2002) Long-term outcome of neoadjuvant therapy for locally advanced breast carcinoma: effective clinical downstaging allows breast preservation and predicts outstanding local control and survival. Ann Surg 236(3):295-302; discussion 302-293. doi:10.1097/01.sla.0000 027526.67560 .64
Carey LA, Metzger R, Dees EC, Collichio F, Sartor CI, Ollila DW, Klauber-DeMore N, Halle J, Sawyer L, Moore DT, Graham ML (2005) American Joint Committee on cancer tumor-node-metastasis stage after neoadjuvant chemotherapy and breast cancer outcome. JNCI J Natl Cancer Inst 97(15):1137-1142. doi:10.1093/ jnci/dji206

Cheang MC, Chia SK, Voduc D, Gao D, Leung S, Snider J, Watson M, Davies S, Bernard PS, Parker JS, Perou CM, Ellis MJ, Nielsen TO (2009) Ki67 index, HER2 status, and prognosis of patients with luminal B breast cancer. J Natl Cancer Inst 101(10):736-750. doi:10.1093/jnci/djp082

Chen AM, Meric-Bernstam F, Hunt KK, Thames HD, Oswald MJ, Outlaw ED, Strom EA, McNeese MD, Kuerer HM, Ross MI, Singletary SE, Ames FC, Feig BW, Sahin AA, Perkins GH, Schechter NR, Hortobagyi GN, Buchholz TA (2004) Breast conservation after neoadjuvant chemotherapy: the MD Anderson cancer center experience. J Clin Oncol 22(12):2303-2312. doi:10.1200/jco.2004.09.062

Colleoni M, Bagnardi V, Rotmensz N, Gelber RD, Viale G, Pruneri G, Veronesi P, Torrisi R, Cardillo A, Montagna E, Campagnoli E, Luini A, Intra M, Galimberti V, Scarano E, Peruzzotti G, Goldhirsch A (2009) Increasing steroid hormone receptors expression defines breast cancer subtypes non responsive to preoperative chemotherapy. Breast Cancer Res Treat 116(2):359-369. doi:10.1007/s10549-008-0223-y

Danforth DN Jr, Lippman ME, McDonald H, Bader J, Egan E, Lampert M, Steinberg SM, Swain SM (1990) Effect of preoperative chemotherapy on mastectomy for locally advanced breast cancer. Am Surg 56(1):6-11

Dawood S, Broglio K, Kau SW, Islam R, Symmans WF, Buchholz TA, McGuire SE, Meric-Bernstam F, Cristofanilli M, Hortobagyi GN, Gonzalez-Angulo AM (2008) Prognostic value of initial clinical disease stage after achieving pathological complete response. Oncologist 13(1):6-15. doi:10.1634/theoncologist.2007-0107

De Placido S, De Laurentiis M, Carlomagno C, Gallo C, Perrone F, Pepe S, Ruggiero A, Marinelli A, Pagliarulo C, Panico L, Pettinato G, Petrella G, Bianco AR (2003) Twenty-year results of the Naples GUN randomized trial: predictive factors of adjuvant tamoxifen efficacy in early breast cancer. Clin Cancer Res 9(3):1039-1046

Dowsett M, Nielsen TO, A'Hern R, Bartlett J, Coombes RC, Cuzick J, Ellis M, Henry NL, Hugh JC, Lively T, McShane L, Paik S, Penault-Llorca F, Prudkin L, Regan M, Salter J, Sotiriou C, Smith IE, Viale G, Zujewski JA, Hayes DF (2011) Assessment of Ki67 in breast cancer: recommendations from the International Ki67 in Breast Cancer working group. J Natl Cancer Inst 103(22):16561664. doi:10.1093/jnci/djr393

Edge SB, Byrd DR, Compton CC, Fritz AG, Greene FL, Trotti A (eds) (2010) American joint committee on cancer staging manual, 7th edn. Springer, New York

Eiermann W, Paepke S, Appfelstaedt J, Llombart-Cussac A, Eremin J, Vinholes J, Mauriac L, Ellis M, Lassus M, Chaudri-Ross HA, Dugan M, Borgs M (2001) Preoperative treatment of postmenopausal breast cancer patients with letrozole: a randomized doubleblind multicenter study. Ann Oncol 12(11):1527-1532

Elston CW, Ellis IO (1991) Pathological prognostic factors in breast cancer. I. The value of histological grade in breast cancer: experience from a large study with long-term follow-up. Histopathology 19(5):403-410

Fisher B, Brown A, Mamounas E, Wieand S, Robidoux A, Margolese RG, Cruz AB Jr, Fisher ER, Wickerham DL, Wolmark N, DeCillis A, Hoehn JL, Lees AW, Dimitrov NV (1997) Effect of preoperative chemotherapy on local-regional disease in women with operable breast cancer: findings from National Surgical Adjuvant Breast and Bowel Project B-18. J Clin Oncol 15(7):2483-2493 
Fisher B, Bryant J, Wolmark N, Mamounas E, Brown A, Fisher ER, Wickerham DL, Begovic M, DeCillis A, Robidoux A, Margolese RG, Cruz AB Jr, Hoehn JL, Lees AW, Dimitrov NV, Bear HD (1998) Effect of preoperative chemotherapy on the outcome of women with operable breast cancer. J Clin Oncol 16(8):26722685

Goldhirsch A, Wood WC, Coates AS, Gelber RD, Thurlimann B, Senn HJ (2011) Strategies for subtypes-dealing with the diversity of breast cancer: highlights of the St. Gallen International Expert Consensus on the Primary Therapy of Early Breast Cancer 2011. Ann Oncol 22(8):1736-1747. doi:10.1093/annonc/mdr304

Green MC, Buzdar AU, Smith T, Ibrahim NK, Valero V, Rosales MF, Cristofanilli M, Booser DJ, Pusztai L, Rivera E, Theriault RL, Carter C, Frye D, Hunt KK, Symmans WF, Strom EA, Sahin AA, Sikov W, Hortobagyi GN (2005) Weekly paclitaxel improves pathologic complete remission in operable breast cancer when compared with paclitaxel once every 3 weeks. J Clin Oncol 23(25):5983-5992. doi:10.1200/jco.2005.06.232

Hortobagyi GN, Ames FC, Buzdar AU, Kau SW, McNeese MD, Paulus D, Hug V, Holmes FA, Romsdahl MM, Fraschini G et al (1988) Management of stage III primary breast cancer with primary chemotherapy, surgery, and radiation therapy. Cancer 62(12):2507-2516

Houssami N, Macaskill P, von Minckwitz G, Marinovich ML, Mamounas E (2012) Meta-analysis of the association of breast cancer subtype and pathologic complete response to neoadjuvant chemotherapy. Eur J Cancer. doi:10.1016/j.ejca.2012.05.023

Huober J, von Minckwitz G, Denkert C, Tesch H, Weiss E, Zahm DM, Belau A, Khandan F, Hauschild M, Thomssen C, Hogel B, DarbEsfahani S, Mehta K, Loibl S (2010) Effect of neoadjuvant anthracycline-taxane-based chemotherapy in different biological breast cancer phenotypes: overall results from the GeparTrio study. Breast Cancer Res Treat 124(1):133-140. doi:10.1007/s10549010-1103-9

Jacquillat C, Weil M, Borel C, Auclerc G, de Maublanc MA, Housset M, Baillet F, Khayat D (1991) Tumor regression as a prognostic factor in breast cancer. Bull Cancer 78(5):435-443

Kaufmann M, Hortobagyi GN, Goldhirsch A, Scholl S, Makris A, Valagussa P, Blohmer JU, Eiermann W, Jackesz R, Jonat W, Lebeau A, Loibl S, Miller W, Seeber S, Semiglazov V, Smith R, Souchon R, Stearns V, Untch M, von Minckwitz G (2006) Recommendations from an international expert panel on the use of neoadjuvant (primary) systemic treatment of operable breast cancer: an update. J Clin Oncol 24(12):1940-1949. doi:10.1200/jco.2005.02.6187

Kaufmann M, Morrow M, von Minckwitz G, Harris JR (2010) Locoregional treatment of primary breast cancer: consensus recommendations from an International Expert Panel. Cancer 116(5):1184-1191. doi:10.1002/cncr.24874

Kim SI, Sohn J, Koo JS, Park SH, Park HS, Park BW (2010) Molecular subtypes and tumor response to neoadjuvant chemotherapy in patients with locally advanced breast cancer. Oncology 79(5-6): 324-330. doi:10.1159/000322192

Kuerer HM, Newman LA, Smith TL, Ames FC, Hunt KK, Dhingra K, Theriault RL, Singh G, Binkley SM, Sneige N, Buchholz TA, Ross MI, McNeese MD, Buzdar AU, Hortobagyi GN, Singletary SE (1999) Clinical course of breast cancer patients with complete pathologic primary tumor and axillary lymph node response to doxorubicin-based neoadjuvant chemotherapy. J Clin Oncol 17(2):460-469

Massarweh S, Osborne CK, Jiang S, Wakeling AE, Rimawi M, Mohsin SK, Hilsenbeck S, Schiff R (2006) Mechanisms of tumor regression and resistance to estrogen deprivation and fulvestrant in a model of estrogen receptor-positive, HER-2/neu-positive breast cancer. Cancer Res 66(16):8266-8273. doi:10.1158/0008-5472.can05-4045
Mauri D, Pavlidis N, Ioannidis JP (2005) Neoadjuvant versus adjuvant systemic treatment in breast cancer: a meta-analysis. J Natl Cancer Inst 97(3):188-194. doi:10.1093/jnci/dji021

McGuire WL, Clark GM, Dressler LG, Owens MA (1986) Role of steroid hormone receptors as prognostic factors in primary breast cancer. NCI Monogr 1:19-23

Meyers MO, Klauber-DeMore N, Ollila DW, Amos KD, Moore DT, Drobish AA, Burrows EM, Dees EC, Carey LA (2011) Impact of breast cancer molecular subtypes on locoregional recurrence in patients treated with neoadjuvant chemotherapy for locally advanced breast cancer. Ann Surg Oncol 18(10):2851-2857. doi:10.1245/s10434-011-1665-8

Min SY, Lee SJ, Shin KH, Park IH, Jung SY, Lee KS, Ro J, Lee S, Kim SW, Kim TH, Kang HS, Cho KH (2011) Locoregional recurrence of breast cancer in patients treated with breast conservation surgery and radiotherapy following neoadjuvant chemotherapy. Int $\mathrm{J}$ Radiat Oncol Biol Phys 81(5):e697-e705. doi:10.1016/j.ijrobp.2010.10.014

Nielsen TO, Parker JS, Leung S, Voduc D, Ebbert M, Vickery T, Davies SR, Snider J, Stijleman IJ, Reed J, Cheang MC, Mardis ER, Perou CM, Bernard PS, Ellis MJ (2010) A comparison of PAM50 intrinsic subtyping with immunohistochemistry and clinical prognostic factors in tamoxifen-treated estrogen receptorpositive breast cancer. Clin Cancer Res 16(21):5222-5232. doi:10.1158/1078-0432.ccr-10-1282

Osborne CK, McGuire WL (1979) The use of steroid hormone receptors in the treatment of human breast cancer: a review. Bull Cancer 66(3):203-209

Peto R, Davies C, Godwin J, Gray R, Pan HC, Clarke M, Cutter D, Darby S, McGale P, Taylor C, Wang YC, Bergh J, Di Leo A, Albain K, Swain S, Piccart M, Pritchard K (2012) Comparisons between different polychemotherapy regimens for early breast cancer: meta-analyses of long-term outcome among 100,000 women in 123 randomised trials. Lancet 379(9814):432-444. doi:10.1016/s0140-6736(11)61625-5

Pierga JY, Mouret E, Laurence V, Dieras V, Savigioni A, Beuzeboc P, Dorval T, Palangie T, Jouve M, Pouillart P (2003) Prognostic factors for survival after neoadjuvant chemotherapy in operable breast cancer. The role of clinical response. Eur $\mathrm{J}$ Cancer 39(8): 1089-1096

Precht LM, Lowe KA, Atwood M, Beatty JD (2010) Neoadjuvant chemotherapy of breast cancer: tumor markers as predictors of pathologic response, recurrence, and survival. Breast J 16(4): 362-368. doi:10.1111/j.1524-4741.2010.00935.x

Romond EH, Perez EA, Bryant J, Suman VJ, Geyer CE Jr, Davidson NE, Tan-Chiu E, Martino S, Paik S, Kaufman PA, Swain SM, Pisansky TM, Fehrenbacher L, Kutteh LA, Vogel VG, Visscher DW, Yothers G, Jenkins RB, Brown AM, Dakhil SR, Mamounas EP, Lingle WL, Klein PM, Ingle JN, Wolmark N (2005) Trastuzumab plus adjuvant chemotherapy for operable HER2-positive breast cancer. N Engl J Med 353(16):1673-1684. doi:10.1056/ NEJMoa052122

Rouzier R, Perou CM, Symmans WF, Ibrahim N, Cristofanilli M, Anderson K, Hess KR, Stec J, Ayers M, Wagner P, Morandi P, Fan C, Rabiul I, Ross JS, Hortobagyi GN, Pusztai L (2005) Breast cancer molecular subtypes respond differently to preoperative chemotherapy. Clin Cancer Res 11(16):5678-5685. doi:10.1158/ 1078-0432.ccr-04-2421

Sachelarie I, Grossbard ML, Chadha M, Feldman S, Ghesani M, Blum RH (2006) Primary systemic therapy of breast cancer. Oncologist 11(6):574-589. doi:10.1634/theoncologist.11-6-574

Sataloff DM, Mason BA, Prestipino AJ, Seinige UL, Lieber CP, Baloch Z (1995) Pathologic response to induction chemotherapy in locally advanced carcinoma of the breast: a determinant of outcome. J Am Coll Surg 180(3):297-306 
Schwartz GF, Birchansky CA, Komarnicky LT, Mansfield CM, Cantor RI, Biermann WA, Fellin FM, McFarlane J (1994) Induction chemotherapy followed by breast conservation for locally advanced carcinoma of the breast. Cancer 73(2):362-369

Semiglazov V, Eiermann W, Zambetti M, Manikhas A, Bozhok A, Lluch A, Tjulandin S, Sabadell MD, Caballero A, Valagussa P, Baselga J, Gianni L (2011) Surgery following neoadjuvant therapy in patients with HER2-positive locally advanced or inflammatory breast cancer participating in the NeOAdjuvant Herceptin (NOAH) study. Eur J Surg Oncol 37(10):856-863. doi:10.1016/ j.ejso.2011.07.003

Straver ME, Rutgers EJ, Rodenhuis S, Linn SC, Loo CE, Wesseling J, Russell NS, Oldenburg HS, Antonini N, Vrancken Peeters MT (2010) The relevance of breast cancer subtypes in the outcome of neoadjuvant chemotherapy. Ann Surg Oncol 17(9):2411-2418. doi:10.1245/s10434-010-1008-1

Tanioka M, Shimizu C, Yonemori K, Yoshimura K, Tamura K, Kouno T, Ando M, Katsumata N, Tsuda H, Kinoshita T, Fujiwara Y (2010) Predictors of recurrence in breast cancer patients with a pathologic complete response after neoadjuvant chemotherapy. Br J Cancer 103(3):297-302. doi:10.1038/sj.bjc.6605769

Untch M, Fasching PA, Konecny GE, Hasmuller S, Lebeau A, Kreienberg R, Camara O, Muller V, du Bois A, Kuhn T, Stickeler E, Harbeck N, Hoss C, Kahlert S, Beck T, Fett W, Mehta KM, von Minckwitz G, Loibl S (2011) Pathologic complete response after neoadjuvant chemotherapy plus trastuzumab predicts favorable survival in human epidermal growth factor receptor 2-overexpressing breast cancer: results from the TECHNO trial of the AGO and GBG study groups. J Clin Oncol 29(25):3351-3357. doi:10.1200/jco.2010.31.4930 van der Hage JA, van de Velde CJ, Julien JP, Tubiana-Hulin M, Vandervelden C, Duchateau L (2001) Preoperative chemotherapy in primary operable breast cancer: results from the European Organization for Research and Treatment of Cancer trial 10902. J Clin Oncol 19(22):4224-4237

von Minckwitz G, Rezai M, Loibl S, Fasching PA, Huober J, Tesch H, Bauerfeind I, Hilfrich J, Eidtmann H, Gerber B, Hanusch C, Kuhn T, du Bois A, Blohmer JU, Thomssen C, Dan Costa S, Jackisch C, Kaufmann M, Mehta K, Untch M (2010) Capecitabine in addition to anthracycline- and taxane-based neoadjuvant treatment in patients with primary breast cancer: phase III GeparQuattro study. J Clin Oncol 28(12):2015-2023. doi:10.1200/jco.2009. 23.8303

von Minckwitz G, Untch M, Nuesch E, Loibl S, Kaufmann M, Kummel S, Fasching PA, Eiermann W, Blohmer JU, Costa SD, Mehta K, Hilfrich J, Jackisch C, Gerber B, du Bois A, Huober J, Hanusch C, Konecny G, Fett W, Stickeler E, Harbeck N, Muller V, Juni P (2011) Impact of treatment characteristics on response of different breast cancer phenotypes: pooled analysis of the German neoadjuvant chemotherapy trials. Breast Cancer Res Treat 125(1):145-156. doi:10.1007/s10549-010-1228-x

von Minckwitz G, Untch M, Blohmer JU, Costa SD, Eidtmann H, Fasching PA, Gerber B, Eiermann W, Hilfrich J, Huober J, Jackisch C, Kaufmann M, Konecny GE, Denkert C, Nekljudova V, Mehta K, Loibl S (2012) Definition and impact of pathologic complete response on prognosis after neoadjuvant chemotherapy in various intrinsic breast cancer subtypes. J Clin Oncol 30(15):1796-1804. doi:10.1200/jco.2011.38.8595 